УДК 676.1.054.1

\title{
СОВЕРШЕНСТВОВАНИЕ ПРОЦЕССА ПОЛУЧЕНИЯ ДРЕВЕСНОВОЛОКНИСТЫХ ПЛИТ СУХИМ СПОСОБОМ
}

\author{
() Н.Г. Чистова ", В.А. Якимов, Ю.Д. Алашкевич \\ Сибирский государственный технологический университет, пр. Мира, 82, \\ Красноярск, 660049 (Россия), e-mail: sibstu@sibstu.kts.ru
}

В статье приведены результаты исследований физико-механических свойств древесноволокнистых плит сухим способом производства (ДВП) с использованием в пресс-массе вермикулитового концентрата и вспученного вермикулита. Установлено, что использование вермикулита при изготовлении плит позволяет получать огнезащищенные ДВП, экономию волокна, при этом уменьшается плотность плит, улучшается прочность при статическом изгибе, уменьшается себестоимость плит.

Объектом исследования является получение ДВП специального назначения сухим способом производства, предметом исследования - процесс подготовки полуфабрикатов при получении древесноволокнистых плит с пониженной пожарной опасностью.

Достоверность результатов работы обеспечивается использованием комплекса современных взаимодополняющих физических, статистическо-математических методов исследований, а также лабораторными и производственными испытаниями, воспроизведением многочисленных опытов, высокой сходимостью расчетных и экспериментальных результатов, согласованностью подходов к процессу подготовки древесноволокнистых материалов с общенаучными положениями, статистической обработкой результатов исследований.

Ключевые слова: древесноволокнистая плита, размол, прочность, плотность, вермикулитовый концентрат, вермикулит вспученный, огнезащита, пресс-масса.

\section{Введение}

Лесопромышленный комплекс России обладает более чем 25\% лесных ресурсов мира, однако современное состояние производства древесноволокнистых плит (ДВП) не позволяет достаточно удовлетворительно решать задачи улучшения используемых в отрасли технологических процессов, создания новых на основе более углубленных теоретических и экспериментальных разработок технологий изготовления ДВП нового поколения, с новыми улучшенными эксплуатационными свойствами [1].

Совершенствование получения ДВП с пониженной пожарной опасностью и низкой себестоимостью является актуальной задачей на современном этапе развития российской экономики [2].

Процесс размола древесноволокнистой массы в ножевых размалывающих машинах зависит от их конструктивных и технологических параметров. Морфологические свойства разработанных волокон, в свою очередь, также оказывают существенное влияние на свойства готовой продукции. Вследствие того, что процессы получения огнезащищенных плит с нужными физико-механическими показателями в настоящее время мало обоснованы теоретически и в основном решаются практическим путем, в работе поставлены следующие задачи:

- обосновать выбор огнезащитного состава с использованием вермикулита для получения ДВП

Чистова Наталья Геральдовна - профессор кафедры ТЛДП, доктор технических наук,

e-mail:sibstu@sibstu.kts.ru

Якимов Вячеслав Анатольевич - аспирант,

e-mail: sibstu@sibstu.kts.ru

Алашкевич Юрий Давыдович - заведующий кафедрой

МАПТ, доктор технических наук, профессор,

e-mail: sibstu@sibstu.kts.ru с пониженной пожарной опасностью;

- определить влияние вермикулитовых компонентов и качественных характеристик древесноволокнистых полуфабрикатов на физико-механические свойства готовых плит с пониженной пожарной опасностью.

\footnotetext{
* Автор, с которым следует вести переписку.
} 
При производстве древесноволокнистых плит сухим и мокрым способами важное место занимают процессы, связанные с физико-механической обработкой древесных волокон: размол древесноволокнистых полуфабрикатов, процессы формирования и прессования древесноволокнистого ковра, закалка и многие другие процессы, влияющие на качественные показатели готовой продукции $[1,2]$.

В настоящее время ставится задача не только увеличить выпуск древесноволокнистых плит, но и научиться быстро перестраивать производственный процесс согласно требованиям заказчика к качеству плиты, ее размерным, геометрическим характеристикам и свойствам.

С целью получения огнезащитных плит огнезащитные составы (водорастворимые и органорастворимые) наносят в основном покрытием или пропиткой (капиллярно-поверхностный способ) [2]. В настоящей работе исследована возможность добавления минерального огнезащитного средства при формировании пресс-массы. Исследования осуществлялись на промышленных установках завода ДВП ЗАО «Новоенисейский ЛХК», а также на экспериментальных и полупромышленных установках лаборатории СибГТУ [4].

Для поддержания оптимального режима технологического процесса производства древесноволокнистых плит необходимо знать взаимосвязи между показателями технологического режима, качеством полуфабрикатов и готовой продукции.

\section{Экспериментальная часть}

В работе был спланирован и реализован трехфакторный эксперимент с использованием В-плана второго порядка с целью определения зависимости физико-механических свойств ДВП (прочности на статический изгиб ( $\sigma_{\text {изг }}$ МПа), плотности ДВП $\left(P\right.$, кг $\left./ \mathrm{M}^{3}\right)$ и водопоглощения за 24 ч $\left.(A, \% ;)\right)$ от массовой доли вермикулита в плите ( $M, \%$ к а.с.в), фракционного показателя качества древесного волокна, фракционных показателей вермикулитового концентрата и вспученного вермикулита [3]. В качестве исходного сырья использовались исключительно древесные отходы лесопильного производства и низкокачественная древесина со склада сырья, породного состава 93 $\pm 3,4 \%$ хвойных пород. В состав пресс-массы включали водный раствор серной кислоты - в качестве осадителя, парафин для придания плитам водостойкости, а в качестве связующего применяли карбамидоформальдегидную смолу.

На основании статистической обработки результатов предварительного эксперимента исследования проводили с параметрами, в наибольшей степени оказывающими влияние на процесс получения огнезащищенных плит: массовая доля вермикулита к а.с.в. в плите (M), фракционный показатель качества древесного волокна (Fr), фракционного показателя вермикулитового концентрата (Frvn) и вспученного вермикулита (Frv). Для установления количественных зависимостей физико-механических свойств готовой плиты (прочность плиты при статическом изгибе $\left(\sigma_{u з}\right)$, плотность $(P)$, водопоглощение за 24 ч $\left.(A)\right)$ выбраны диапазоны варьирования исследуемых факторов:

$$
2 \leq M \leq 6 ; \quad 29 \leq F r \leq 33 ; 0,1 \leq F r v \leq 0,5 ; \quad 0,5 \leq F r v n \leq 1,5 .
$$

Планирование и реализация многофакторных исследований представлены в виде функциональной зависимости:

$$
\sigma_{\text {изг }}, P, A=f(M, F r, \text { Frv. Frvn). }
$$

Регрессионные зависимости, описывающие влияния технологических параметров процесса получения огнезащищенных ДВП (массовой доли вермикулита в плите, фракционного показателя качества древесного волокна, фракционного показателя вермикулитового концентрата) на их физико-механические свойства, будут иметь вид:

$$
\begin{aligned}
& \sigma_{\text {изг } v}=-48,88-1,25 \cdot M+255,9 \cdot F r-228,11 \cdot F r v n-0,05 \cdot M^{2}-4,04 \cdot F r^{2}+44,88 \cdot F r v n^{2}- \\
& -0,08 \cdot M \cdot F r+2,36 \cdot M \cdot F r v n+3,83 \cdot F r \cdot F r v n \\
& \operatorname{Pr}_{v n}=-970,11+1,42 \cdot M+8,21 \cdot F r-17,69 \cdot F r v n-0,09 \cdot M^{2}-0,12 \cdot F r^{2}-0,69 \cdot F r v n^{2}- \\
& -0,13 \cdot M \cdot F r+0,12 \cdot M \cdot F r v n+0,52 \cdot F r \cdot F r v n \\
& \quad A_{v n}=21,24-0,78 \cdot M-0,93 \cdot F r-1,89 \cdot F r v n+0,01 \cdot M^{2}-0,02 \cdot F r^{2}+2,58 \cdot F r v n^{2}- \\
& -0,06 \cdot M \cdot F r-0,1 \cdot M \cdot F r v n+0,52 \cdot F r \cdot F r v n .
\end{aligned}
$$


В таблице представлены результаты экспериментальных исследований зависимости физикомеханических свойств ДВП (прочности на статический изгиб, плотности ДВП и водопоглощения за 24 ч) от массовой доли вермикулита в плите, фракционного показателя качества древесного волокна, фракционного показателя вермикулитового концентрата и вспученного вермикулита.

Зависимость физико-механических свойств ДВП от массовой доли вермикулита в плите, фракционного показателя качества древесного волокна, фракционного показателя вермикулитового концентрата и вспученного вермикулита

\begin{tabular}{c|c|c|c|c|c|c|c|c|c|c}
\hline & $M$ & $F r$ & $F r v n$ & $F r v$ & $\sigma_{\text {изг }} n$ & $\sigma_{\text {изг }} v$ & $P v n$ & $P v$ & $A v n$ & $A v$ \\
\hline 1 & 15 & 29 & 0,5 & 0,1 & 40,44 & 41,5 & 823,4 & 822,4 & 27,45 & 29,52 \\
2 & 45 & 29 & 0,5 & 0,1 & 43,97 & 44,1 & 844,36 & 843,22 & 23,48 & 25,78 \\
3 & 15 & 33 & 0,5 & 0,1 & 43,56 & 46,2 & 875,36 & 876,67 & 20,36 & 22,49 \\
4 & 45 & 33 & 0,5 & 0,1 & 44,89 & 45 & 851,96 & 852,3 & 22,54 & 24,6 \\
5 & 15 & 29 & 1,5 & 0,5 & 39,01 & 38,3 & 804,65 & 805,9 & 28,64 & 30,98 \\
6 & 45 & 29 & 1,5 & 0,5 & 42,3 & 40,2 & 818,22 & 817,21 & 27,15 & 29,76 \\
7 & 15 & 33 & 1,5 & 0,5 & 43,6 & 43,9 & 836,92 & 837,93 & 27,14 & 28,19 \\
8 & 45 & 33 & 1,5 & 0,5 & 45,89 & 46,9 & 876,23 & 878,28 & 21,04 & 22,56 \\
9 & 15 & 31 & 1 & 0,3 & 45,1 & 45 & 853,47 & 852,3 & 21,61 & 23,78 \\
10 & 45 & 31 & 1 & 0,3 & 42,9 & 43,9 & 839,2 & 839,2 & 26,57 & 28,2 \\
11 & 30 & 29 & 1 & 0,3 & 46,52 & 43,2 & 838,2 & 838,2 & 22,23 & 24,63 \\
12 & 30 & 33 & 1 & 0,3 & 44,87 & $41-, 5$ & 824,48 & 822,6 & 21,05 & 23,5 \\
13 & 30 & 31 & 0,5 & 0,1 & 46,32 & 46,2 & 877,45 & 877,33 & 22,38 & 24,3 \\
14 & 30 & 31 & 1,5 & 0,5 & 44,35 & 43,9 & 840,01 & 839,6 & 22,21 & 25,4 \\
\hline
\end{tabular}

Регрессионные зависимости, описывающие физико-механические свойства ДВП от массовой доли вермикулита в плите, фракционного показателя качества древесного волокна и фракционного показателя вспученного вермикулита, будут иметь вид:

$$
\begin{aligned}
& \quad \sigma_{v}=-34,72+0,30 \cdot M+30,65 \cdot F r-85,53 \cdot F r v+0,07 \cdot M^{2}-0,49 \cdot F r^{2}+18,91 \cdot F r v^{2}- \\
& \quad-0,01 \cdot M \cdot F r+0,15 \cdot M \cdot F r v+2,09 \cdot F r \cdot F r v \\
& P_{v}=-830,47+3,45 \cdot M+250,43 \cdot F r-165,64 \cdot F r v-0,09 \cdot M^{2}-3,99 \cdot F r^{2}+275,51 \cdot F r v^{2}- \\
& -0,11 \cdot M \cdot F r+2,73 \cdot M \cdot F r v+24,81 \cdot F r \cdot F r v
\end{aligned}
$$

$$
\begin{aligned}
& A_{v}=29,28+0,19 \cdot M-21,21 \cdot F r+39,27 \cdot F r v-0,56 \cdot M^{2}+0,33 \cdot F r^{2}-14,25 \cdot F r v^{2}+ \\
& +0,06 \cdot M \cdot F r-0,22 \cdot M \cdot F r v-0,56 \cdot F r \cdot F r v
\end{aligned}
$$

Все уравнения регрессии были проверены на адекватность. По моделям с натуральными значениями факторов проведен статистический анализ, дана интерпретация роли указанных факторов и их парного взаимодействия, математически установлены количественные взаимосвязи между исследуемыми параметрами.

Использование уравнений позволяет прогнозировать получение влияния огнезащитных компонентов и качественных характеристик древесноволокнистых полуфабрикатов на физико-механические свойства готовых плит с пониженной пожарной опасностью, подбирать составы огнезащитных пресс-масс в технологии изготовления огнезащищенных ДВП сухим способом производства.

\section{Обсуждение результатов}

Графические интерпретации полученных в результате исследований статистическо-математических зависимостей физико-механических свойств древесноволокнистых плит с пониженной пожароопасностью от каждого из исследуемых факторов позволяют достаточно точно выполнить их анализ, описать и установить взаимосвязи исследуемых показателей.

На рисунке 1 в качестве примера представлены графические зависимости, построенные по уравнениям для плотности, прочности и водопоглощения за 24 ч огнезащищенных древесноволокнистых плит от массовой доли вермикулита в плите, фракционного показателя качества древесного волокна, фракционного показателя вермикулитового концентрата для двух факторов из трех. 

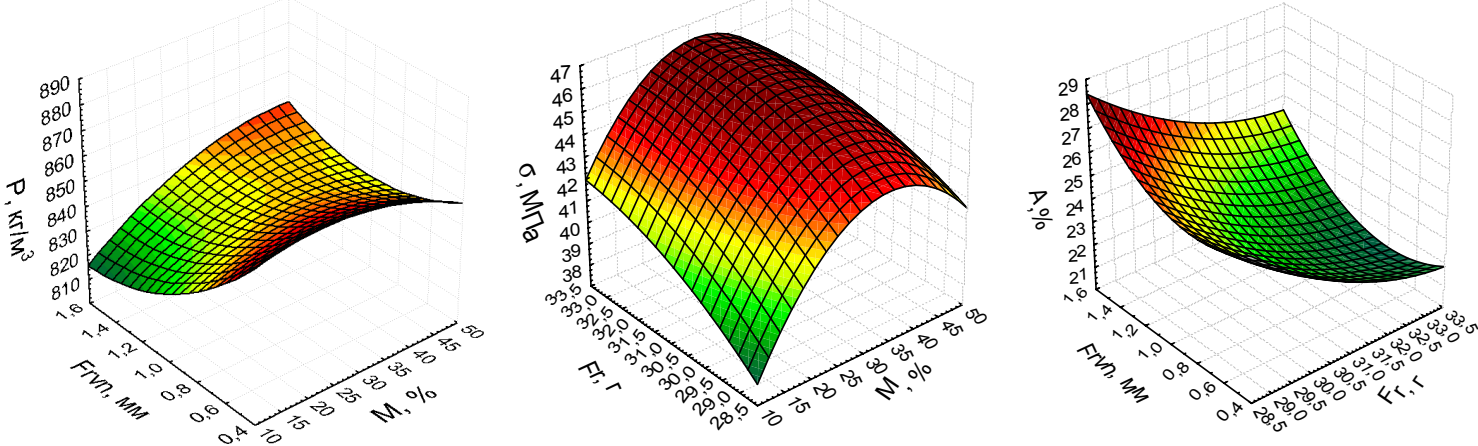

Рис. 1. Зависимость прочности, плотности и водопоглощения за 24 ч ДВП от массовой доли вермикулита в плите, фракционного показателя качества древесного волокна, фракционного показателя вермикулитового концентрата

В качестве примера на рисунке 2 представлена графическая интерпретация зависимости физикомеханических свойств огнезащищенных ДВП от исследуемых технологических параметров процесса подготовки огнезащищенных плит.

Как показали результаты исследований [1], вермикулитовые компоненты не препятствовали снижению упругости и повышению пластичности древесных волокон в процессе формирования ковра и прессования плит, которые обеспечивают увеличение удельной поверхности волокон, развитие поверхностного натяжения и образование межволоконных связей в плите, тем самым сохраняя прочность готового изделия; не оказывали отрицательного воздействия на адгезионные связи древесного волокна со связующим, не препятствовали отверждению связующего; вермикулит нерастворим, не содержит органических растворителей, нелетуч и нетоксичен, не содержит дефицитных и дорогостоящих компонентов, таких как антипирены.

Исследования также показали, что наибольшее влияние на физико-механические свойства древесноволокнистых плит оказывают фракционный состав волокна, гранулометрический состав вермикулита и его массовая доля в плите. В отличие от производства ДВП мокрым способом, где часть вермикулита удаляется с водой в подсеточные воды в процессе формования древесного ковра, в производстве ДВП сухим способом обеспечивается его присутствие в полном объеме в ковре и равномерность распределения, что обуславливает сохранение качественных показателей ДВП с одновременным приданием им свойств огнестойкости $[1,2]$.

Пластификация и размягчение древесных волокон в процессе горячего прессования начинается при более низких температурах, при установленном давлении прессования, в результате чего достигается большая поверхность контакта, чем при таком же давлении в процессе прессования волокна того же фракционного состава без вермикулита. В результате уменьшаются значения плотности плиты, по сравнению с обычной плитой.
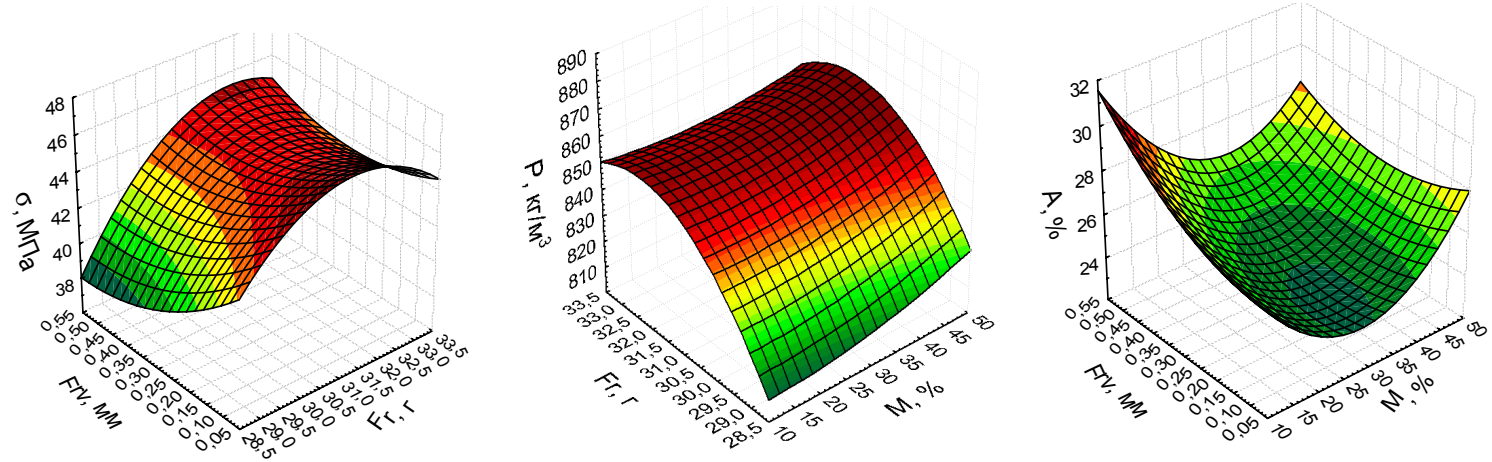

Рис. 2. Зависимости прочности, плотности и водопоглощения за 24 ч ДВП от массовой доли вермикулита в плите, фракционного показателя качества древесного волокна, фракционного показателя вспученного вермикулита 
На рисунке 3 представлены фотографии, подтверждающие результативность использования вермикулитовых компонентов при изготовлении древесноволокнистых плит сухим способом производства.

Как известно, прочность древесины и, соответственно, плиты характеризуется анизотропией, обусловленной анатомическим и надмолекулярным строением [2].

Как показали исследования $[1,2]$, при горячем прессовании вермикулитовый компонент взаимодействует с компонентами древесного волокна, совмещая это взаимодействие с основными процессами образования плит (возникновением межволоконных связей, поликонденсацией связующего и др.). Качество последних сохранится в полной мере, а по некоторым показателям даже улучшится. Вермикулитовый компонент активно участвует в происходящих при прессовании и закалке плит процессах. Он способствует пластификации древесного волокна с образованием пространственных сшивок (мостичные связи), что приводит к повышению прочностных характеристик готового материала.

Таким образом, при формировании структуры огнезащитных древесноволокнистых плит сухим способом производства с использованием вермикулита, наряду с возникновением и развитием межволоконного взаимодействия, обеспечивается создание прочных клеевых соединений «волокно-связующеевермикулит». Вводимые в древесноволокнистый ковер химические добавки и огнезащитные компоненты не только способствуют межволоконному взаимодействию и обеспечивают хорошие физико-механические показатели плит, но и придают конечной продукции специальные огнезащитные свойства.

Получение ДВП на основе вермикулита является экологически чистым, нетоксичным, биологически стойким. Материал не подвержен разложению и гниению под действием микроорганизмов, препятствует распространению плесени, не является благоприятной средой для насекомых и грызунов. Вермикулитовый компонент химически инертен: нейтрален к действию щелочей и кислот.

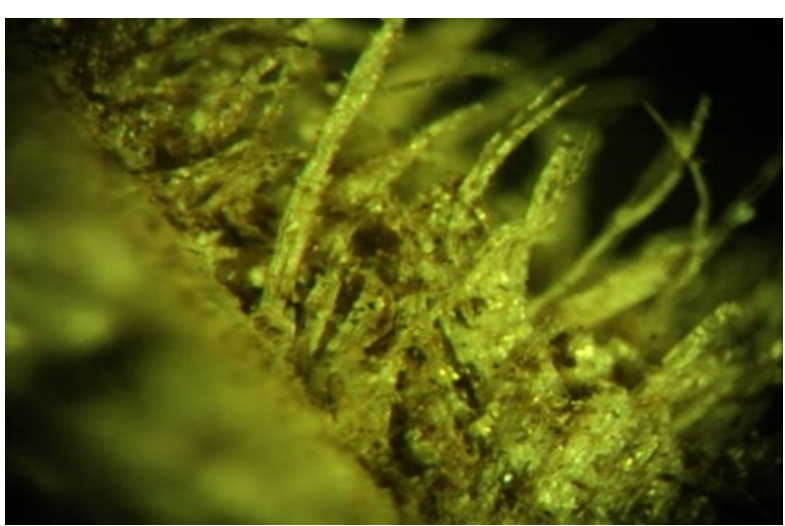

а) увеличение 980 крат

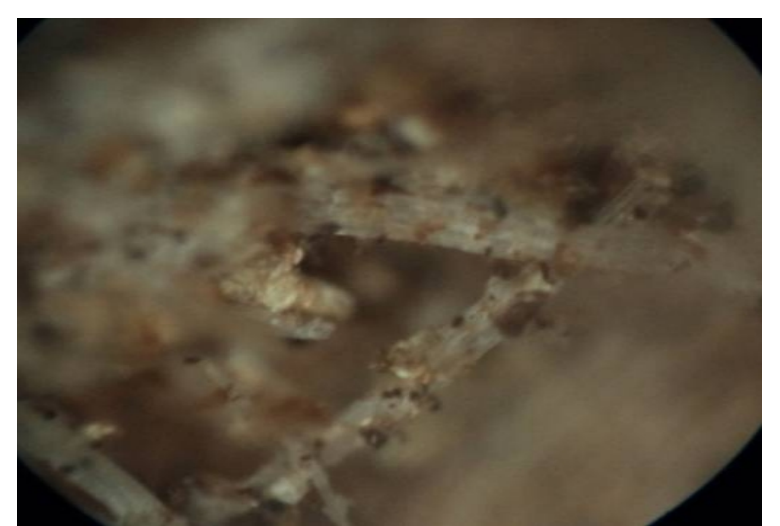

б) увеличение 1500 крат

Рис. 3. Фотографии древесноволокнистого ковра с включениями вермикулитовых компонентов

\section{Выводы}

Исследования показали, что наибольшее влияние на физико-механические свойства древесноволокнистых плит оказывают гранулометрический состав вермикулита и его массовая доля в плите, обеспечивается его равномерность распределения в ковре при сохранении основных физико-механических показателей на уровне требований ГОСТ 4598-86.

Снижение пожарной опасности древесноволокнистых плит, полученных сухим способом, достигается тем, что композиция для их получения, включающая древесноволокнистую массу, гидрофобные добавки и синтетическое связующее, дополнительно содержит огнезащитный компонент - вермикулит при следующем соотношении составных частей, \%: древесноволокнистая масса - 83,5-63,5; вермикулит - 10 30; парафин - 1; смола карбамидоформальдегидная - 3; аммоний хлористый - 0,3; карбамид - 1,2; серная кислота - 1, при этом размеры частиц (фракций) вермикулита могут изменяться от 0,1 до 1,4 мм.

Размер фракций вспученного вермикулита для введения в композицию подобран опытным путем. Использование фракций с размерами более 1,4 мм приводит к ухудшению физико-механических показателей готовой продукции.

Качество, экологичность и себестоимость ДВП с использованием вермикулита, а также технологичность их обработки обеспечит этим плитам конкурентные преимущества, по сравнению с другими плитами специального назначения. 


\section{Список литературы}

1. Чистова Н.Г. Переработка древесных отходов в технологическом процессе получения древесноволокнистых плит : дис. ... докт. техн. наук. Красноярск, 2010. 415 с.

2. Леонович А.А., Шелоумов А.В. Снижение пожарной опасности древесных материалов, изделий строительных конструкций. СПб., 2002. 59 с.

3. Пижурин А.А., Пижурин А.А. Моделирование и оптимизация процессов деревообработки. М., 2004. 375 с.

4. Заявка на патент № 2009613683 (РФ). Численный метод определения секундной режущей длины секторной ножевой гарнитуры дисковых мельниц с параллельными прямолинейными ножами постоянной ширины / А.А. Набиева, Е.Е. Нестеров, Ю.Д. Алашкевич, Д.С. Карпенко // 10.07.2009.

Поступило в редакичию 24 февраля 2016 г.

После переработки 19 мая 2016 г. BOARD

Chistova N.G.*, Yakimov V.A., Alashkevich Iu.D. IMPROVING THE PROCESS OF SPECIAL PURPOSE FIBRE-

Siberian State Technological University, ul. Mira, 82, Krasnoyarsk, 660049 (Russia), e-mail: sibstu@sibstu.kts.ru

The results of studies of physical and mechanical properties of fiberboard production by dry method (MDF) using presmasse vermiculite concentrate and expanded vermiculite. It was found that the use of vermiculite in the manufacture of the plates produces Fire resistant MDF, fiber savings, reducing the density of the plate, improves durability at a static bend, decreases the cost of the plates.

Object of research - getting fiberboard special purpose dry process production. fire hazard.

Subject of research - the process of preparation of semi-finished products in the preparation of fibreboard with reduced

Objective - To develop the scientific basis of reduce fire danger fibreboard made by dry method.

The process of grinding the wood fiber supply in knife grinding machines depends on their design and process parameters. Morphological properties developed fibers, in turn, also have a significant effect on the properties of the finished product. Since the processes of obtaining Fire resistant boards with the right physical and mechanical properties are currently not enough substantiated theoretically and basically solved in a practical way, in the following tasks: production;

- Determine the composition of the special manufacturing techniques in presmass Fire resistant hardboard dry process

- Determine the effect of flame retardant components and quality characteristics of wood-fiber semi-finished products on the physico-mechanical properties of the finished boards with a reduced fire hazard.

Keywords: fibreboard, grinding, strength, density, expanded vermiculite, fire protection, presmassa, ecology, vermiculite concentrate.

\section{References}

1. Chistova N.G. Pererabotka drevesnykh otkhodov v tekhnologicheskom protsesse polucheniia drevesnovoloknistykh plit : dis.... d-ra tekhn. nauk. [Recycling wood waste in the process producing fibreboard: the dissertation of the doctor of technical sciences]. Krasnoyarsk, 2010, 461 p. (in Russ.).

2. Leonovich A.A. Snizhenie pozharnoi opasnosti drevesnykh materialov, izdelii i stroitel'nykh konstruktsii. [Reduced fire hazard wood-based materials, products and building structures]. St. Petersburg, 2002, 59 p. (in Russ.).

3. Pizhurin A.A., Pizhurin A.A. Modelirovanie i optimizatsiia protsessov derevoobrabotki. [Simulation and Optimization of wood]. Moscow, 2004, 375 p. (in Russ.).

4. The patent application 2009613683 (RU). 10.07.2009.

Received February 24, 2016

Revised May 19, 2016

\footnotetext{
* Corresponding author.
} 